\title{
Mn- and Co-Catalyzed Aminocyclizations of Unsaturated Hydrazones Providing a Broad Range of Functionalized Pyrazolines
}

\author{
Journal Article \\ Author(s): \\ Balkenhohl, Moritz; Koelbl, Sebastian; Georgiev, Tony; Carreira, Erick M. (D) \\ Publication date: \\ 2021-07-26 \\ Permanent link: \\ https://doi.org/10.3929/ethz-b-000500769 \\ Rights / license: \\ Creative Commons Attribution-NonCommercial-NoDerivatives 4.0 International \\ Originally published in: \\ JACS Au 1(7), https://doi.org/10.1021/jacsau.1c00176 \\ Funding acknowledgement: \\ 833540 - Development of Stereoselective Olefin Functionalization Methods (EC)
}




\title{
Mn- and Co-Catalyzed Aminocyclizations of Unsaturated Hydrazones Providing a Broad Range of Functionalized Pyrazolines
}

\author{
Moritz Balkenhohl, Sebastian Kölbl, Tony Georgiev, and Erick M. Carreira*
}

Cite This: JACS Au 2021, 1, 919-924

Read Online

\section{ACCESS}

Џlll Metrics \& More

回 Article Recommendations

Supporting Information

ABSTRACT: Manganese- and cobalt-catalyzed aminocyclization reactions of unsaturated hydrazones are reported. Whereas manganese catalysis provides access to pyrazoline and tetrahydropyridazine alcohols, cobalt catalysis for the first time paves the way for the selective formation of pyrazoline aldehydes. Furthermore, various functional groups including hydroperoxide, thiol derivatives, iodide, and bicyclopentane may be introduced via manganese-catalyzed ring-forming aminofunctionalization. A progesterone receptor antagonist was prepared using the aminocyclization protocol.

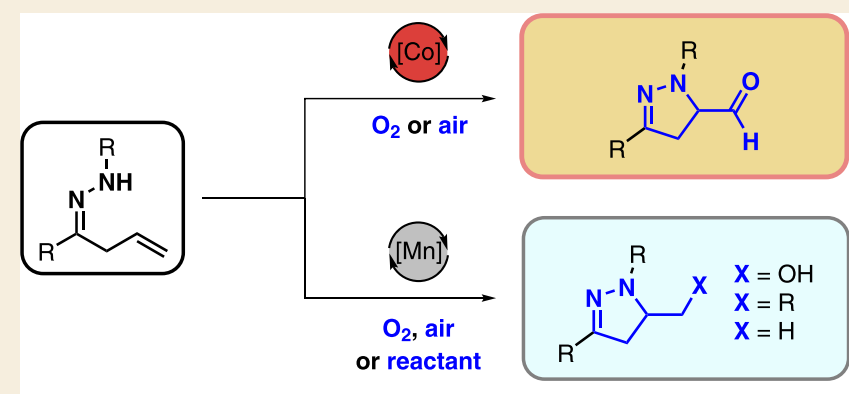

- One-Step Transformation - Redox Efficient - Divergent -

KEYWORDS: Aminocyclization, Cobalt, Manganese, Pyrazolines, Hydrazones, Oxygen, Aldehyde

\begin{abstract}
zoles such as pyrazoles are important building blocks in modern pharmaceutical and agrochemical industry. ${ }^{1-6}$ Partially saturated counterparts, in particular 2-pyrazolines, are gaining recognition as promising scaffolds, ${ }^{7,8}$ as they offer great opportunity for structural diversification, which has proven to be key in modern drug development. ${ }^{9,10}$ In parallel, there has been great interest in building blocks that provide possibilities for design beyond the two-dimensional space of traditional (hetero)aromatic rings. ${ }^{9,10}$ Accordingly, leads incorporating 2pyrazolines have appeared in drug discovery programs for treatment of a wide range of diseases, including cancer, ${ }^{8 b, d}$ diabetes, ${ }^{8 \mathrm{~g}}$ and malaria. ${ }^{8 \mathrm{e}}$ They have also shown antiinflammatory, $^{8 \mathrm{c}}$-microbial, ${ }^{8 \mathrm{e}}$ and -fungal activity (Scheme 1A). ${ }^{8 f}$ Hence, approaches that lead to this scaffold with diverse functional groups are especially valuable. Herein we report selective manganese- and cobalt-catalyzed aminocyclization reactions of unsaturated hydrazones $\mathbf{I}$ that provide a wide variety of functionalized pyrazolines, including aldehydes, alcohols, peroxide, thiol derivatives, iodide, and bicyclopentane (II-VIII, Scheme 1B).

Pyrazolines have commonly been prepared via 1,3-dipolar cycloadditions $^{11,12}$ or condensation reactions of enones and hydrazines. ${ }^{11 \mathrm{~b}, 13,14}$ Recently, Cu-catalyzed oxidative cyclization of unsaturated hydrazones has been reported to give pyrazolines. ${ }^{15}$ However, this process affords a mixture of aldehydes II (20\%), alcohols III (18\%), and hydroperoxides IV (40\%), thus requiring a subsequent reductive step to convert the mixture into alcohol products. There have also been reports on the use of acridinium ${ }^{16}$ and ruthenium ${ }^{17}$ photocatalysis to furnish pyrazolines, such as III and $\mathbf{V} .^{18-20}$ Collectively, these approaches demonstrate the general interest
\end{abstract}

Scheme 1. Biologically Active Pyrazolines and Cyclization Reactions of Unsaturated Hydrazones

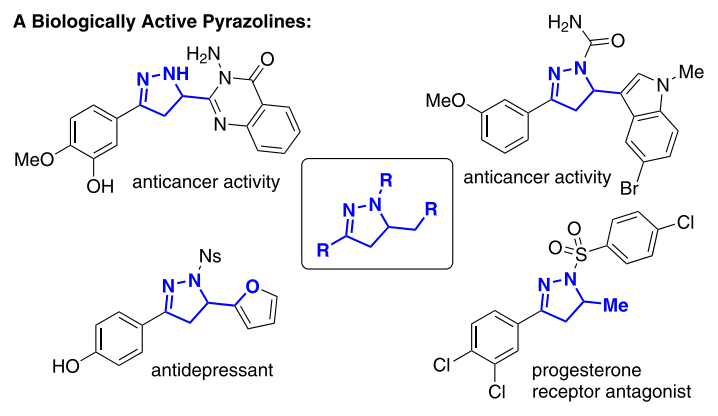

B This Work: - One-Step Transformation - Redox Efficient - Divergent -

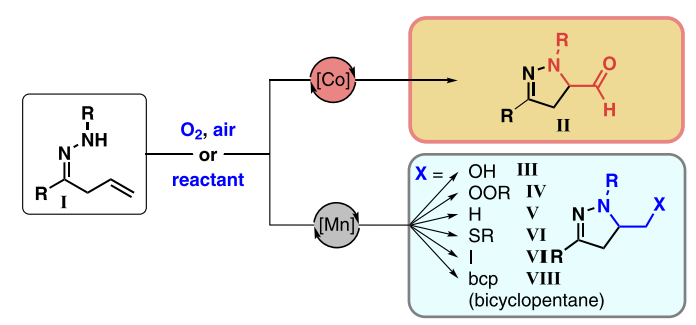

Published: June 11, 2021

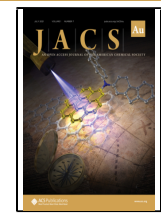


in methods for the preparation of functionalized pyrazolines. However, convenient access is desirable not only to alcohols but also to an expanded set of products that include other groups. These would be especially useful because they may serve as linchpins for further synthetic elaboration. In this respect, selective and efficient access to aldehydes, such as II in Scheme 1B, has not been reported, despite the fact that they act as a gateway to other functionalities, such as carboxylic acids, amides, nitriles, amines, and heterocycles. Chemler reported the aerobic copper-catalyzed cyclization of 4pentenylsulfonamides to yield 2-formylpyrrolidines, which were then subjected to oxidative $\mathrm{C}-\mathrm{C}$ bond cleavage and further transformed into 2-pyrrolidinones. ${ }^{21,22}$

Catalysis by first-row transition metals has gained significant attention because of their low cost and natural abundance. ${ }^{23}$ The use of manganese and cobalt catalysis remains relatively underexplored for olefin functionalizations in comparison with other transition metals such as copper, palladium, and nickel, ${ }^{24-26}$ yet it offers great opportunities. We have been inspired by one of the earliest examples of preparatively useful cobalt-catalyzed olefin functionalization, namely, the Mukaiyama hydration, ${ }^{27,28}$ and related processes. ${ }^{29,30}$

Our prospecting studies commenced by examination of hydrazone 1a as a prototype in a variety of cyclization reactions (Table 1). Extensive optimization studies $^{31}$ revealed that

Table 1. Selected Optimization Results for the Mn- and CoCatalyzed Cyclizations

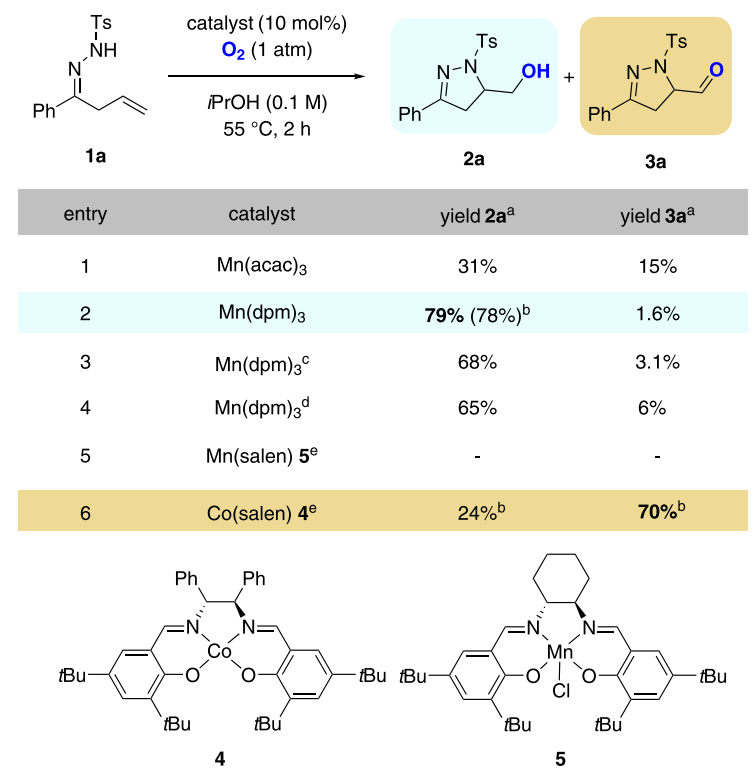

${ }^{a}$ Determined by ${ }^{1} \mathrm{H}$ NMR spectroscopy with 1,3,5-trimethoxybenzene as the internal standard. ${ }^{b}$ Isolated yield. ${ }^{c}$ Air was continuously introduced into the reaction mixture. ${ }^{d}$ The reaction was conducted at $25{ }^{\circ} \mathrm{C}$ for $12 \mathrm{~h}$. ${ }^{e}$ The reaction was conducted at $25{ }^{\circ} \mathrm{C}$ for $1 \mathrm{~h}$.

treatment of $1 \mathrm{a}$ with $\mathrm{Mn}(\mathrm{acac})_{3}(10 \mathrm{~mol} \%)$ under an oxygen atmosphere $(1 \mathrm{~atm})$ in isopropanol $(0.1 \mathrm{M})$ at $55{ }^{\circ} \mathrm{C}$ for $2 \mathrm{~h}$ afforded pyrazoline alcohol $\mathbf{2 a}$ in $31 \%$ yield alongside the corresponding aldehyde $3 \mathbf{a}$ in $15 \%$ yield (Table 1 , entry 1$){ }^{32}$ Switching to $\mathrm{Mn}(\mathrm{dpm})_{3}(\mathrm{dpm}=$ dipivaloylmethanato $)$ significantly improved the reaction outcome and selectivity, providing $\mathbf{2 a}$ in $79 \%$ yield and $3 \mathrm{a}$ in merely $1.6 \%$ yield (2a:3a ratio $=98: 2)$ (entry 2$)$. The use of air via a gas inlet instead of a pure oxygen atmosphere furnished alcohol $2 \mathrm{a}$ in $68 \%$ yield (entry 3). This result was satisfying, as especially on larger scales the handling of molecular oxygen can be hazardous. ${ }^{33}$ Lowering the reaction temperature to $25{ }^{\circ} \mathrm{C}$ was also feasible with an elongated reaction time ( $12 \mathrm{~h}, 65 \%$ yield; entry 4$)$. In examining other catalysts (see the Supporting Information), we observed that cobalt salen 4 resulted in a change in the reaction outcome, affording aldehyde $3 a$ in $70 \%$ yield, whereas manganese salen 5 did not lead to product formation (entries 5 and 6) . . $^{31,34}$

With the optimized reaction parameters in hand for cyclization and selective formation of alcohols, the scope of the reaction was investigated (Scheme 2). Various $\beta, \gamma$ -

\section{Scheme 2. Mn-Catalyzed Cyclizations}

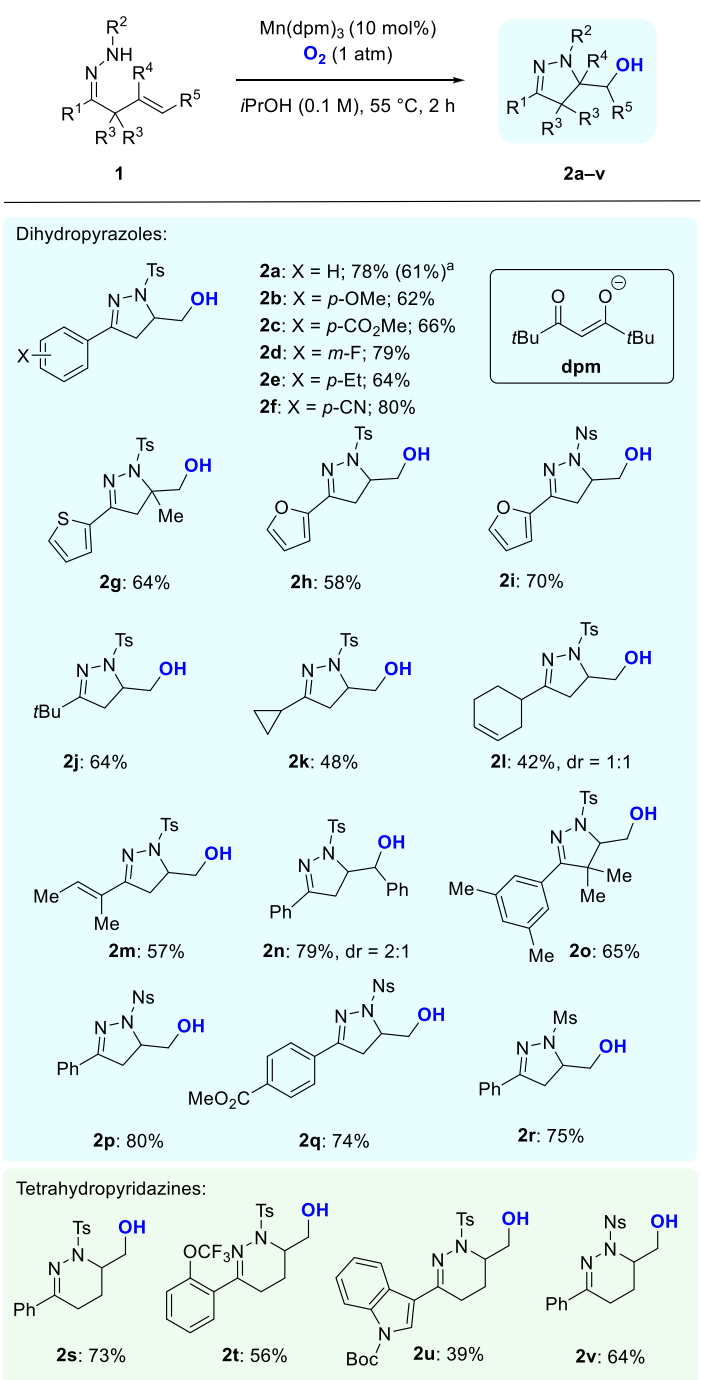

${ }^{a_{T}}$ The reaction was conducted on a $4 \mathrm{mmol}$ scale.

unsaturated aryl- and heteroarylhydrazones were submitted to the established reaction conditions, and $\mathrm{N}$-heterocycles $\mathbf{2 a -}$ i were obtained in 58-80\% yield. Esters and nitriles were welltolerated in the cyclization reaction, and no difference in reactivity was observed for substrates incorporating electrondonating and -withdrawing substituents. The use of alkylhydrazones as substrates led to the formation of pyrazolines $\mathbf{2 j}-\mathbf{l}$ in $42-64 \%$ yield. In the presence of additional olefins, which could participate in competitive cyclizations, only 5-exo-trig 
cyclization was observed, and $\mathrm{N}$-heterocycles $\mathbf{2 l}$ and $\mathbf{2 m}$ were isolated in $42 \%$ and $57 \%$ yield, respectively. Substrates with substituents on the alkyl chain $(\mathbf{1 g}, \mathbf{1 n}$, and 1o) were also employed and provided, after cyclization, pyrazolines $2 \mathrm{~g}$, 2n, and 20 in $64-79 \%$ yield. Replacing the $N$-tosyl group with $N$ nosyl ( $p$-nitrophenylsulfonyl) or $N$-mesyl (methylsulfonyl) was also possible, giving rise to pyrazolines $2 \mathrm{i}$ and $2 \mathrm{p}-\mathbf{r}$ in $70-80 \%$ yield. When $\gamma, \delta$-unsaturated hydrazones were submitted to the reaction conditions, tetrahydropyridazines $2 \mathbf{s}-\mathbf{v}$ were obtained in $39-73 \%$ yield.

We then investigated substrates in which the alkene partner was embedded within a ring, which would lead to ring-fused or spiro-pyrazolines (Scheme 3). Hydrazones $\mathbf{5 a - c}$ as starting

Scheme 3. Preparation of Fused and Spiro Pyrazolines

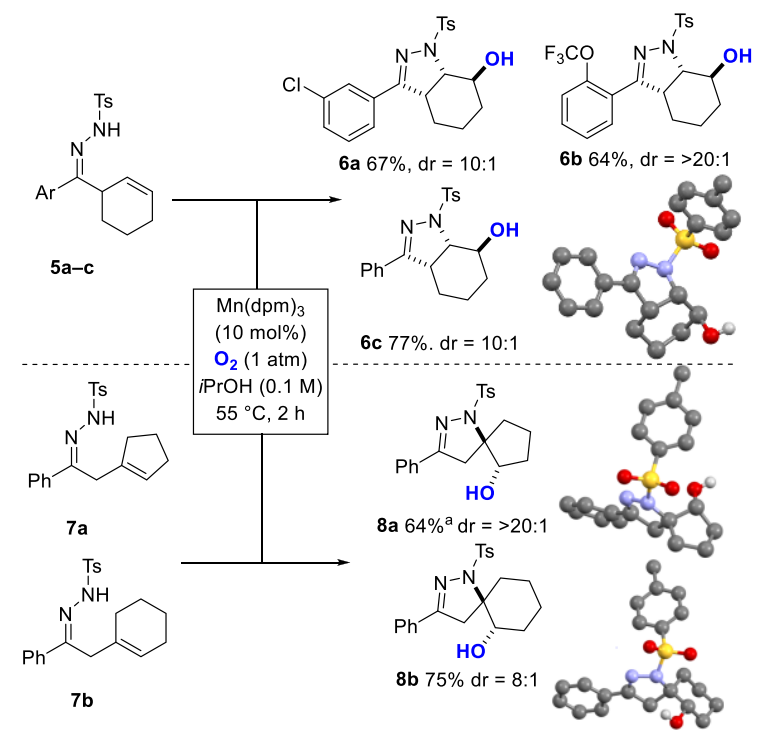

${ }^{a} \mathrm{Mn}(\mathrm{dpm})_{3}(20 \mathrm{~mol} \%)$ was used.

materials provided valuable 5,6-fused bicyclic rings $\mathbf{6 a - c}$ possessing an anti relative configuration (64-77\% yield, $\mathrm{dr}$ 10:1 to $>20: 1)$, as determined by ${ }^{1} \mathrm{H}$ NMR, X-ray, and $1 \mathrm{D}$ NOE data (Scheme 3). ${ }^{35,36}$ When cyclopentene- and cyclohexene-substituted hydrazones $7 \mathbf{a}$ and $7 \mathbf{b}$ were used, [4.4] and [4.5] spirocycles $\mathbf{8 a}$ and $\mathbf{8 b}$ were prepared in high yields with excellent diastereoselectivity (64\% and $75 \%$ yield, $\mathrm{dr}>20: 1$ and 8:1, respectively; Scheme 3).

During the optimization studies aimed at preparation of the primary alcohol product shown in Table 1, we observed that the formation of aldehyde $3 a$ was preferred with the use of Cosalen 4 as catalyst (see Table 1, entry 6). Given the rather limited number of examples of cyclization reactions of olefins that produce aldehydes, we set out to investigate the scope of this transformation (Scheme 4). Various functional groups including nitriles and esters were well-tolerated, yielding aldehydes $3 \mathbf{a}-\mathbf{f}$ in $46-83 \%$ yield. ${ }^{37}$ Replacing the oxygen atmosphere by air via a gas inlet led to $3 a$ in $57 \%$ yield. When furan and thiophene hydrazones were employed, pyrazolines $3 \mathrm{~g}$ and $3 \mathrm{~h}$ were isolated in $63 \%$ and $53 \%$ yield, respectively. Other sulfonamides could be used, such as $N$-mesyl and $N$ nosyl, yielding aldehydes $3 \mathbf{i}$ and $3 \mathbf{j}$, both in $47 \%$ yield (Scheme 4). We speculate that the cobalt catalyst mediates cyclization, formation of a terminal hydroperoxide, and its collapse to aldehydes $3 \mathbf{a}-\mathbf{j}$. $^{38}$
Scheme 4. Co-Catalyzed Cyclizations
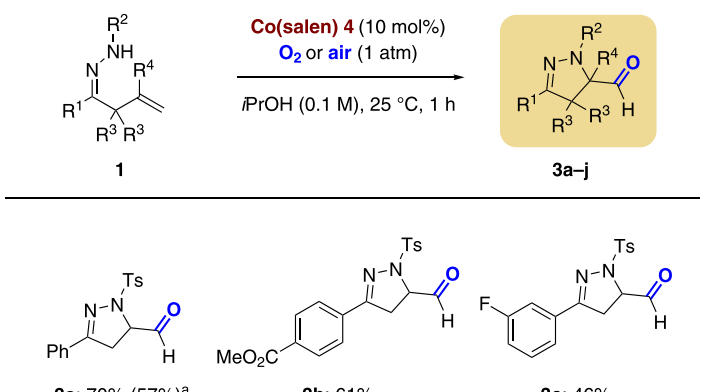

$\begin{array}{lll}\text { 3a: } 70 \%(57 \%)^{\text {a }} & \text { 3b: } 61 \% & \text { 3c: } 46 \%\end{array}$
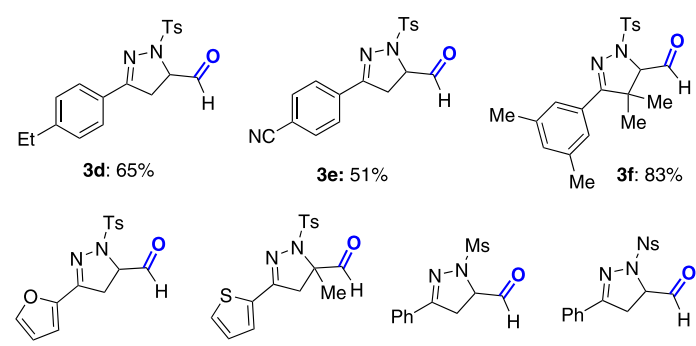

$3 g: 63 \%$<smiles>[Y9]C1(C([2H])=O)CC(c2cccs2)=NN1[13CH3]</smiles><smiles>CS(=O)(=O)N1N=C(c2ccccc2)CC1C=O</smiles><smiles>NN1N=C(c2ccccc2)CC1C=O</smiles>

3h: $53 \%$

3i: $47 \%$

3j: $47 \%$

${ }^{a}$ Air was continuously introduced into the reaction mixture.

We then proceeded to examine the use of other reactive traps instead of oxygen (Scheme 5). After prospecting experiments, we found a standard set of conditions in which stirring $1 \mathrm{a}$ with various reactants in the presence of $\mathrm{Mn}(\mathrm{dpm})_{3}$

\section{Scheme 5. Mn-Catalyzed Aminofunctionalizations}

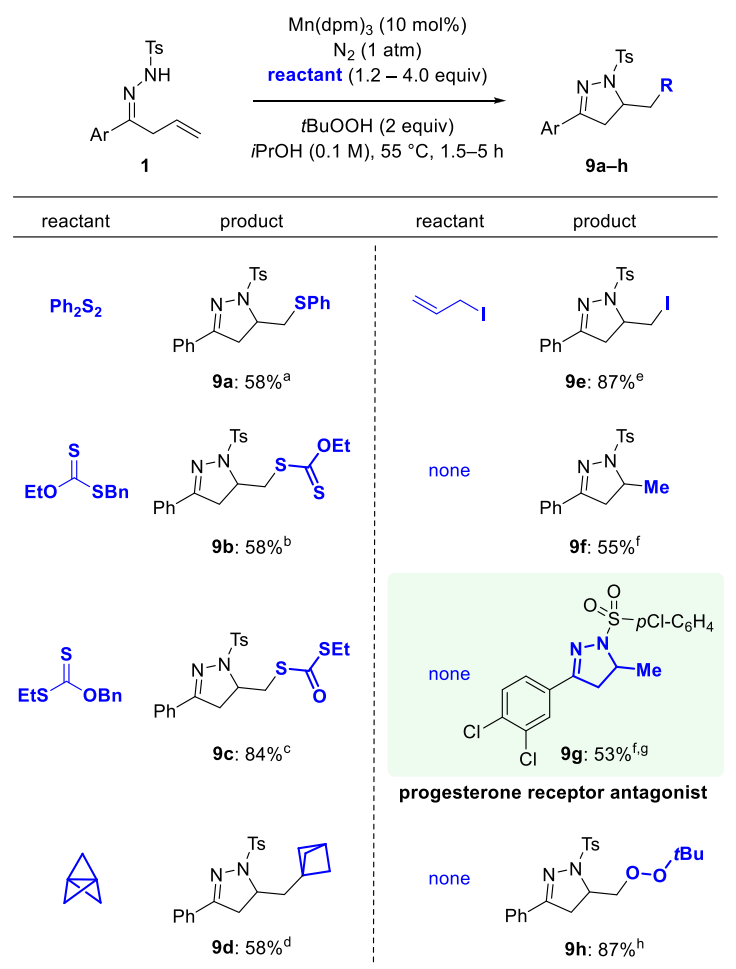

${ }^{a}$ Diphenyl disulfide as the reactant. ${ }^{b} S$-benzyl O-ethyl carbonodithioate as the reactant. ${ }^{c} O$-benzyl $S$-ethyl carbonodithioate as the reactant. ${ }^{d}[1.1 .1]$ propellane as the reactant. ${ }^{e}$ allyl iodide as the reactant. ${ }^{f}$ No reactant. ${ }^{g} \mathrm{Mn}(\mathrm{dpm})_{3}(30 \mathrm{~mol} \%)$ was used. ${ }^{h}$ No reactant; DCE was used as the solvent. 
$(10 \mathrm{~mol} \%)$ and $t \mathrm{BuOOH}$ (2 equiv) in $\mathrm{PrOH}$ under $\mathrm{N}_{2}(1$ atm) gave a variety of adducts. In the presence of diphenyl disulfide ( 2 equiv) thioether 9 a was formed in $58 \%$ yield. The reaction of 1 with $S$-benzyl $O$-ethyl carbonodithioate and $O$ benzyl $S$-ethyl carbonodithioate afforded xanthate $\mathbf{9 b}$ and carbonodithioate $9 \mathrm{c}$ in $58 \%$ and $84 \%$ yield, respectively. With [1.1.1] propellane, bicyclopentane derivative 9d was obtained in $58 \%$ yield. The use of allyl iodide afforded primary iodide $9 \mathrm{e}$ in $87 \%$ yield. Interestingly, in the absence of additional reactants, treatment of 1 a with $\mathrm{Mn}(\mathrm{dpm})_{3}(10 \mathrm{~mol} \%)$ and $t \mathrm{BuOOH}$ (2 equiv) in $\mathrm{PrOH}$ under $\mathrm{N}_{2}(1 \mathrm{~atm})$ provided $9 \mathrm{f}$ in $55 \%$ yield. ${ }^{39}$ When the appropriate unsaturated hydrazone was employed as the starting material it was possible to prepare pyrazoline $9 \mathrm{~g}$, a progesterone receptor antagonist, ${ }^{8 \mathrm{a}}$ in $53 \%$ yield. In cyclizations leading to $9 \mathbf{f}$ and $\mathbf{9 g}$, $\mathrm{PrOH}$ acts as a hydrogen donor, as described in the early work of Mukaiyama. ${ }^{34,40}$ When the reaction was conducted in DCE instead of $i \mathrm{PrOH}$, tert-butylhydroperoxide quenched the reactive intermediate to give dialkyl peroxide $9 \mathbf{h}$ in $87 \%$ yield (Scheme 5).

Finally, various synthetic transformations were performed using pyrazoline and tetrahydropyridazine alcohols (Scheme 6). ${ }^{35}$ Reaction of $2 \mathrm{a}$ with $\mathrm{Bu}_{4} \mathrm{NF}$ led to elimination of the $\mathrm{N}$ -

Scheme 6. Derivatization of the Pyrazolines and Tetrahydropyridazine

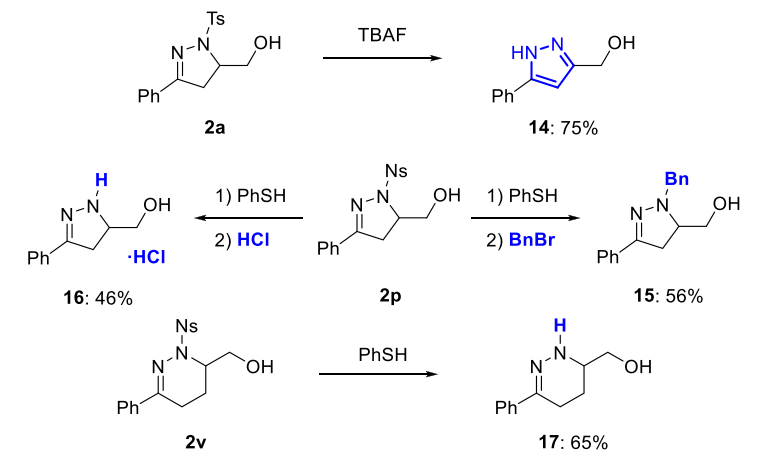

tosyl group, which provided pyrazole 14 in $75 \%$ yield. When $\mathrm{N}$-nosyl pyrazoline $2 \mathrm{p}$ was treated with thiophenol at room temperature in the presence of $\mathrm{K}_{2} \mathrm{CO}_{3}$ followed by benzyl bromide, pyrazoline 15 was obtained in $56 \%$ yield. ${ }^{41}$ It was also possible to prepare the corresponding hydrochloride salt 16 in $46 \%$ yield by addition of $2 \mathrm{M} \mathrm{HCl}$ in dioxane after sulfonamide cleavage. ${ }^{42}$ Removal of the $\mathrm{N}$-nosyl group from tetrahydropyridazine $2 \mathbf{v}$ could also be carried out, affording azine $\mathbf{1 7}$ in $65 \%$ yield (Scheme 6).

In summary, we have disclosed manganese- and cobaltcatalyzed cyclization reactions of unsaturated hydrazones that gave divergent access to a range of complex and highly functionalized $\mathrm{N}$-heterocycles. Whereas aerobic manganese catalysis led to the formation of pyrazoline and tetrahydropyridazine alcohols, a cobalt-salen catalyst for the first time allowed the preparation of pyrazoline aldehydes. Addition of various reactants to the cyclization reaction paved the way for the formation of a variety of functionalized pyrazolines as well as a progesterone receptor antagonist. Finally, synthetic transformations of the prepared products were performed, demonstrating the utility of the cyclization protocol. We are in the process of further developing cyclization reactions that lead to versatile aldehyde products, and the results will be reported as they become available.

\section{ASSOCIATED CONTENT \\ Supporting Information}

The Supporting Information is available free of charge at https://pubs.acs.org/doi/10.1021/jacsau.1c00176.

- Full experimental details, crystallographic data, and ${ }^{1} \mathrm{H}$ and ${ }^{13} \mathrm{C}$ spectra (PDF)

- Crystallographic data for $\mathbf{8 a}$ (CIF)

- Crystallographic data for 6c (CIF)

- Crystallographic data for $\mathbf{8 b}$ (CIF)

- Crystallographic data for 9d (CIF)

- Crystallographic data for 14 (CIF)

\section{AUTHOR INFORMATION}

\section{Corresponding Author}

Erick M. Carreira - Laboratorium für Organische Chemie, Eidgenössische Technische Hochschule Zürich, 8093 Zürich, Switzerland; 이이.org/0000-0003-1472-490X;

Email: erickm.carreira@org.chem.ethz.ch

\section{Authors}

Moritz Balkenhohl - Laboratorium für Organische Chemie, Eidgenössische Technische Hochschule Zürich, 8093 Zürich, Switzerland

Sebastian Kölbl - Laboratorium für Organische Chemie, Eidgenössische Technische Hochschule Zürich, 8093 Zürich, Switzerland

Tony Georgiev - Laboratorium für Organische Chemie, Eidgenössische Technische Hochschule Zürich, 8093 Zürich, Switzerland

Complete contact information is available at:

https://pubs.acs.org/10.1021/jacsau.1c00176

Notes

The authors declare no competing financial interest.

\section{ACKNOWLEDGMENTS}

This work was funded by the European Research Council (OLECAT, Grant ID 833540). M.B. thanks the Deutsche Forschungsgemeinschaft (DFG) for a postdoctoral fellowship. We are grateful to Dr. N. Trapp and M. Solar for X-ray crystallographic analysis.

\section{REFERENCES}

(1) Lednicer, D. Drugs Based on Five-Membered Heterocycles. In Strategies for Organic Drug Synthesis and Design, 2nd ed.; Wiley: Hoboken, NJ, 2009; pp 239-318.

(2) Baumann, M.; Baxendale, I. R.; Ley, S. V.; Nikbin, N. An overview of the key routes to the best selling 5-membered ring heterocyclic pharmaceuticals. Beilstein J. Org. Chem. 2011, 7, 442495.

(3) Lamberth, C. Heterocyclic chemistry in crop protection. Pest Manage. Sci. 2013, 69, 1106-1114.

(4) Vitaku, E.; Smith, D. T.; Njardarson, J. T. Analysis of the Structural Diversity, Substitution Patterns, and Frequency of Nitrogen Heterocycles among U.S. FDA Approved Pharmaceuticals. J. Med. Chem. 2014, 57, 10257-10274.

(5) Taylor, A. P.; Robinson, R. P.; Fobian, Y. M.; Blakemore, D. C.; Jones, L. H.; Fadeyi, O. Modern advances in heterocyclic chemistry in drug discovery. Org. Biomol. Chem. 2016, 14, 6611-6637. 
(6) Heravi, M. M.; Zadsirjan, V. Prescribed drugs containing nitrogen heterocycles: an overview. RSC Adv. 2020, 10, 4424744311.

(7) For reviews, see: (a) Liu, X. H.; Ruan, B. F.; Li, J.; Chen, F. H.; Song, B. A.; Zhu, H. L.; Bhadury, P. S.; Zhao, J. Synthesis and Biological Activity of Chiral Dihydropyrazole: Potential Lead for Drug Design. Mini-Rev. Med. Chem. 2011, 11, 771-821. (b) Matiadis, D.; Sagnou, M. Pyrazoline Hybrids as Promising Anticancer Agents: An Up-to-Date Overview. Int. J. Mol. Sci. 2020, 21, 5507.

(8) For recent examples, see: (a) Jones, D. G.; Liang, X.; Stewart, E. L.; Noe, R. A.; Kallander, L. S.; Madauss, K. P.; Williams, S. P.; Thompson, S. K.; Gray, D. W.; Hoekstra, W. J. Discovery of nonsteroidal mifepristone mimetics: Pyrazoline-based PR antagonists. Bioorg. Med. Chem. Lett. 2005, 15, 3203-3206. (b) Wang, P.-F.; Qiu, H.-Y.; Baloch, S. K.; Gong, H.-B.; Wang, Z.-C.; Zhu, H.-L. Synthesis, Biological Evaluation, and Docking of Dihydropyrazole Sulfonamide Containing 2-hydroxyphenyl Moiety: A Series of Novel MMP-2 Inhibitors. Chem. Biol. Drug Des. 2015, 86, 1405-1410. (c) Korablina, D. D.; Vorozhtsov, N. I.; Sviridova, L. A.; Kalenikova, E. I.; Medvedev, O. S. Pharmacological Activity of 4,5-Dihydropyrazole Derivatives. Pharm. Chem. J. 2016, 50, 281-295. (d) Sebastian, J. Dihydropyrazole and dihydropyrrole structures based design of Kif15 inhibitors as novel therapeutic agents for cancer. Comput. Biol. Chem. 2017, 68, 164-174. (e) Mishra, V. K.; Mishra, M.; Kashaw, V.; Kashaw, S. K. Synthesis of 1,3,5-trisubstituted pyrazolines as potential antimalarial and antimicrobial agents. Bioorg. Med. Chem. 2017, 25, 1949-1962. (f) Abdelrahmman, K.; El-Behairy, M. F.; Alsherbiny, M. A.; Mazeed, T. E. In vitro activity of dihydropyrazole derivatives against Candida species. Bull. Fac. Pharm. 2018, 56, 80-82. (g) Shi, J.; Gu, Z.; Jurica, E. A.; Wu, X.; Haque, L. E.; Williams, K. N.; Hernandez, A. S.; Hong, Z.; Gao, Q.; Dabros, M.; Davulcu, A. H.; Mathur, A.; Rampulla, R. A.; Gupta, A. K.; Jayaram, R.; Apedo, A.; Moore, D. B.; Liu, H.; Kunselman, L. K.; Brady, E. J.; Wilkes, J. J.; Zinker, B. A.; Cai, H.; Shu, Y.-Z.; Sun, Q.; Dierks, E. A.; Foster, K. A.; Xu, C.; Wang, T.; Panemangalore, R.; Cvijic, M. E.; Xie, C.; Cao, G. G.; Zhou, M.; Krupinski, J.; Whaley, J. M.; Robl, J. A.; Ewing, W. R.; Ellsworth, B. A. Discovery of Potent and Orally Bioavailable Dihydropyrazole GPR40 Agonists. J. Med. Chem. 2018, 61, 681-694. (h) Tripathi, A. C.; Upadhyay, S.; Paliwal, S.; Saraf, S. K. Derivatives of 4,5-dihydro$(1 H)$ pyrazoles as possible MAO-A inhibitors in depression and anxiety disorders: synthesis, biological evaluation and molecular modeling studies. Med. Chem. Res. 2018, 27, 1485-1503.

(9) Lovering, F.; Bikker, J.; Humblet, C. Escape from Flatland: Increasing Saturation as an Approach to Improving Clinical Success. J. Med. Chem. 2009, 52, 6752-6756.

(10) Carreira, E. M.; Fessard, T. C. Four-Membered RingContaining Spirocycles: Synthetic Strategies and Opportunities. Chem. Rev. 2014, 114, 8257-8322.

(11) For reviews, see: (a) Stanley, L. M.; Sibi, M. P. Enantioselective Copper-Catalyzed 1,3-Dipolar Cycloadditions. Chem. Rev. 2008, 108, 2887-2902. (b) Farooq, S.; Ngaini, Z. One-Pot and Two-Pot Synthesis of Chalcone Based Mono and Bis-Pyrazolines. Tetrahedron Lett. 2020, 61, 151416.

(12) For selected examples, see: (a) Chen, J.-R.; Dong, W.-R.; Candy, M.; Pan, F.-F.; Jörres, M.; Bolm, C. Enantioselective Synthesis of Dihydropyrazoles by Formal $[4+1]$ Cycloaddition of in SituDerived Azoalkenes and Sulfur Ylides. J. Am. Chem. Soc. 2012, 134, 6924-6927. (b) Rueping, M.; Maji, M. S.; Küçük, H. B.; Atodiresei, I. Asymmetric Brønsted Acid Catalyzed Cycloadditions-Efficient Enantioselective Synthesis of Pyrazolidines, Pyrazolines, and 1,3Diamines from N-Acyl Hyrazones and Alkenes. Angew. Chem., Int. Ed. 2012, 51, 12864-12868. (c) Zhang, D.-Y.; Shao, L.; Xu, J.; Hu, X.-P. Copper-Catalyzed Asymmetric Formal $[3+2]$ Cycloaddition of Propargylic Acetates with Hydrazines: Enantioselective Synthesis of Optically Active 2-Pyrazolines. ACS Catal. 2015, 5, 5026-5030. (d) Hu, S.; Du, S.; Yang, Z.; Ni, L.; Chen, Z. Synthesis of Multisubstituted Dihydropyrazoles by Copper-Mediated [4+1] Cycloaddition Reaction of N-Sulfonylhydrazones and Sulfoxonium Ylides. Adv. Synth. Catal. 2019, 361, 3124-3136.
(13) Léavai, A. Synthesis of 2-pyrazolines by the reactions of $\alpha, \beta$ unsaturated aldehydes, ketones, and esters with diazoalkanes, nitrile imines, and hydrazines. J. Heterocycl. Chem. 2002, 39, 1-13.

(14) Yusuf, M.; Jain, P. Synthetic and biological studies of pyrazolines and related heterocyclic compounds. Arabian J. Chem. 2014, 7, 553-596.

(15) Chen, S.; Chen, W.; Chen, X.; Chen, G.; Ackermann, L.; Tian, $\mathrm{X}$. Copper(I)-Catalyzed Oxyamination of $\beta, \gamma$-Unsaturated Hydrazones: Synthesis of Dihydropyrazoles. Org. Lett. 2019, 21, 77877790.

(16) Hu, X.-Q.; Chen, J.; Chen, J.-R.; Yan, D.-M.; Xiao, W.-J. Organophotocatalytic Generation of $\mathrm{N}$ - and $\mathrm{O}$-Centred Radicals Enables Aerobic Oxyamination and Dioxygenation of Alkenes. Chem. - Eur. J. 2016, 22, 14141-14146.

(17) Hu, X.-Q.; Chen, J.-R.; Wei, Q.; Liu, F.-L.; Deng, Q.-H.; Beauchemin, A. M.; Xiao, W.-J. Photocatalytic Generation of NCentered Hydrazonyl Radicals: A Strategy for Hydroamination of $\beta, \gamma$ Unsaturated Hydrazones. Angew. Chem., Int. Ed. 2014, 53, 1216312167.

(18) For cyclizations of $\beta, \gamma$-unsaturated hydrazones, which contain an $\alpha$-quaternary center, to give pyrazolines, see: (a) Duan, X.-Y.; Yang, X.-L.; Fang, R.; Peng, X.-X.; Yu, W.; Han, B. Hydrazone Radical Promoted Vicinal Difunctionalization of Alkenes and Trifunctionalization of Allyls: Synthesis of Pyrazolines and Tetrahydropyridazines. J. Org. Chem. 2013, 78, 10692-10704. (b) Zhao, Q.-Q.; Chen, J.; Yan, D.-M.; Chen, J.-R.; Xiao, W.-J. Photocatalytic Hydrazonyl Radical-Mediated Radical Cyclization/Allylation Cascade: Synthesis of Dihydropyrazoles and Tetrahydropyridazines. Org. Lett. 2017, 19, 3620-3623. (c) Chen, M.; Wang, L.-J.; Ren, P.-X.; Hou, X.-Y.; Fang, Z.; Han, M.-N.; Li, W. Copper-Catalyzed Diamination of Alkenes of Unsaturated Ketohydrazones with Amines. Org. Lett. 2018, 20, 510513. (d) Wang, L.-J.; Ren, P.-X.; Qi, L.; Chen, M.; Lu, Y.-L.; Zhao, J.Y.; Liu, R.; Chen, J.-M.; Li, W. Copper-Mediated Aminoazidation, Aminohalogenation, and Aminothiocyanation of $\beta, \gamma$-Unsaturated Hydrazones: Synthesis of Versatile Functionalized Pyrazolines. Org. Lett. 2018, 20, 4411-4415. (e) Liu, R.-H.; Wang, Z.-Q.; Wei, B.-Y.; Zhang, J.-W.; Zhou, B.; Han, B. Cu-Catalyzed Aminoacyloxylation of Unactivated Alkenes of Unsaturated Hydrazones with Manifold Carboxylic Acids toward Ester-Functionalized Pyrazolines. Org. Lett. 2018, 20, 4183-4186. (f) Chen, M.; Qi, L.; Chen, J.-M.; Ren, P.-X.; $\mathrm{Du}$, J.; Wang, L.-J.; Li, W. Synthesis of acyloxyl pyrazolines by coppermediated aminoacyloxylation of unsaturated ketohydrazones. Org. Biomol. Chem. 2018, 16, 5136-5143.

(19) For an example using phenylhydrazones, see: Zhu, M.-K.; Chen, Y.-C.; Loh, T.-P. Radical-Mediated Diamination of Alkenes with Phenylhydrazine and Azodicarboxylates: Highly Diastereoselective Synthesis of trans-Diamines from Cycloalkenes. Chem. - Eur. J. 2013, 19, 5250-5254.

(20) For an example using hypervalent iodine, see: Hu, X.-Q.; Feng, G.; Chen, J.-R.; Yan, D.-M.; Zhao, Q.-Q.; Wei, Q.; Xiao, W.-J. $\mathrm{PhI}(\mathrm{OAc})_{2}$-mediated functionalisation of unactivated alkenes for the synthesis of pyrazoline and isoxazoline derivatives. Org. Biomol. Chem. 2015, 13, 3457-3461.

(21) Wdowik, T.; Chemler, S. R. Direct Synthesis of 2Formylpyrrolidines, 2-Pyrrolidinones and 2-Dihydrofuranones via Aerobic Copper-Catalyzed Aminooxygenation and Dioxygenation of 4-Pentenylsulfonamides and 4-Pentenylalcohols. J. Am. Chem. Soc. 2017, 139, 9515-9518.

(22) For related $\mathrm{Au} / \mathrm{Fe}$ - or $\mathrm{Cu}$-catalyzed cyclizations, see: (a) de Haro, T.; Nevado, C. Flexible Gold-Catalyzed Regioselective Oxidative Difunctionalization of Unactivated Alkenes. Angew. Chem., Int. Ed. 2011, 50, 906-910. (b) Wang, H.; Wang, Y.; Liang, D.; Liu, L.; Zhang, J.; Zhu, Q. Copper-Catalyzed Intramolecular Dehydrogenative Aminooxygenation: Direct Access to Formyl-Substituted Aromatic N-Heterocycles. Angew. Chem., Int. Ed. 2011, 50, 56785681. (c) Toh, K. K.; Wang, Y.-F.; Ng, E. P. J.; Chiba, S. CopperMediated Aerobic Synthesis of 3-Azabicyclo[3.1.0]hex-2-enes and 4Carbonylpyrroles from N-Allyl/Propargyl Enamine Carboxylates. J. Am. Chem. Soc. 2011, 133, 13942-13945. (d) Peng, H.; Akhmedov, 
N. G.; Liang, Y.-F.; Jiao, N.; Shi, X. Synergistic Gold and Iron Dual Catalysis: Preferred Radical Addition toward Vinyl-Gold Intermediate over Alkene. J. Am. Chem. Soc. 2015, 137, 8912-8915.

(23) For recent reviews, see: (a) Gandeepan, P.; Müller, T.; Zell, D.; Cera, G.; Warratz, S.; Ackermann, L. 3d Transition Metals for C-H Activation. Chem. Rev. 2019, 119, 2192-2452. (b) St John-Campbell, S.; Bull, J. A. Base Metal Catalysis in Directed C(sp3)-H Functionalisation. Adv. Synth. Catal. 2019, 361, 3662-3682.

(24) The Chemistry of Organomanganese Compounds; Rappoport, Z., Marek, I.,Eds.; Wiley, 2011.

(25) Dhungana, R. K.; Kc, S.; Basnet, P.; Giri, R. Transition MetalCatalyzed Dicarbofunctionalization of Unactivated Olefins. Chem. Rec. 2018, 18, 1314-1340.

(26) Cobalt Catalysis in Organic Synthesis: Methods and Reactions; Hapke, M., Hilt, G., Eds.; Wiley-VCH: Weinheim, Germany, 2020.

(27) Isayama, S.; Mukaiyama, T. A New Method for Preparation of Alcohols from Olefins with Molecular Oxygen and Phenylsilane by the Use of Bis(acetylacetonato)cobalt(II). Chem. Lett. 1989, 18, 1071-1074.

(28) For reviews, see: (a) Waser, J.; Gaspar, B.; Nambu, H.; Carreira, E. M. Hydrazines and Azides via the Metal-Catalyzed Hydrohydrazination and Hydroazidation of Olefins. J. Am. Chem. Soc. 2006, 128, 11693-11712. (b) Crossley, S. W. M.; Obradors, C.; Martinez, R. M.; Shenvi, R. A. Mn-, Fe-, and Co-Catalyzed Radical Hydrofunctionalizations of Olefins. Chem. Rev. 2016, 116, 89129000. (c) Zweig, J. E.; Kim, D. E.; Newhouse, T. R. Methods Utilizing First-Row Transition Metals in Natural Product Total Synthesis. Chem. Rev. 2017, 117, 11680-11752. (d) Green, S. A.; Crossley, S. W. M.; Matos, J. L. M.; Vásquez-Céspedes, S.; Shevick, S. L.; Shenvi, R. A. The High Chemofidelity of Metal-Catalyzed Hydrogen Atom Transfer. Acc. Chem. Res. 2018, 51, 2628-2640.

(29) For cobalt-catalyzed aerobic cyclizations of unsaturated alcohols that provide tetrahydrofurans, see: (a) Inoki, S.; Mukaiyama, T. A Convenient Method for the Stereoselective Preparation of trans-2-Hydroxymethyltetrahydrofurans by the Oxidative Cyclization of 5-Hydroxy-1-alkenes with Molecular Oxygen Catalyzed by Cobalt(II) Complex. Chem. Lett. 1990, 19, 67-70. (b) Palmer, C.; Morra, N. A.; Stevens, A. C.; Bajtos, B.; Machin, B. P.; Pagenkopf, B. L. Increased Yields and Simplified Purification with a Second-Generation Cobalt Catalyst for the Oxidative Formation of trans-THF Rings. Org. Lett. 2009, 11, 5614-5617. (c) Schuch, D.; Fries, P.; Dönges, M.; Pérez, B. M.; Hartung, J. Reductive and Brominative Termination of Alkenol Cyclization in Aerobic CobaltCatalyzed Reactions. J. Am. Chem. Soc. 2009, 131, 12918-12920.

(30) For cobalt- and manganese-catalyzed aerobic cyclizations of unsaturated oximes that provide dihydroisoxazoles, see: (a) Li, W.; Jia, P.; Han, B.; Li, D.; Yu, W. Cobalt-catalyzed aerobic oxidative cyclization of $\beta, \gamma$-unsaturated oximes. Tetrahedron 2013, 69, 32743280. (b) Yamamoto, D.; Oguro, T.; Tashiro, Y.; Soga, M.; Miyashita, K.; Aso, Y.; Makino, K. Manganese-Promoted Oxidative Cyclization of Unsaturated Oximes Using Molecular Oxygen in Air under Ambient Conditions. Eur. J. Org. Chem. 2016, 2016, 5216-5219.

(31) For full screening details, see the Supporting Information.

(32) Determined by ${ }^{1} \mathrm{H}$ NMR analysis using trimethoxybenzene as an internal standard.

(33) Hone, C. A.; Roberge, D. M.; Kappe, C. O. The Use of Molecular Oxygen in Pharmaceutical Manufacturing: Is Flow the Way to Go? ChemSusChem 2017, 10, 32-41.

(34) TEMPO trapping experiments led to the formation of the corresponding TEMPO adduct (see the Supporting Information). We tentatively posit a reaction mechanism in which a nitrogen-centered radical is formed and then undergoes cyclization to give a carboncentered radical intermediate that is trapped by oxygen. Depending on the nature of the catalyst, this species could collapse to either alcohol 2a or aldehyde 3a. Similar reaction pathways of metal peroxo species were described in early work by Mukaiyama. See: Mukaiyama, T.; Isayama, S.; Inoki, S.; Kato, K.; Yamada, T.; Takai, T. OxidationReduction Hydration of Olefins with Molecular Oxygen and 2Propanol Catalyzed by Bis(acetylacetonato)cobalt(II). Chem. Lett.
1989, 18, 449-452. However, at this point in time we cannot rule out reactions of $\mathrm{Mn}-$ or $\mathrm{Co}$-hydrazone adducts with olefins, with trapping of the corresponding organometal intermediates by oxygen.

(35) For further details, see the Supporting Information.

(36) CCDC 2078368 (6c), CCDC 2078369 (8a), CCDC 2078370 (8b), CCDC 2078371 (9d), and CCDC 2078372 (14) contain the supplementary crystallographic data for this paper. These data can be obtained free of charge from The Cambridge Crystallographic Data Centre via www.ccdc.cam.ac.uk/data_request/cif.

(37) Reduction of 3a to alcohol $2 \mathrm{a}$ using $\mathrm{NaBH}_{4}$ (1.1 equiv, THF $\left.(0.1 \mathrm{M}), 25{ }^{\circ} \mathrm{C}, 1 \mathrm{~h}\right)$ followed by chiral SFC analysis of the alcohol did not show enantiomeric enrichment.

(38) When the cobalt-catalyzed reaction was conducted at $0{ }^{\circ} \mathrm{C}$, exclusive formation of the hydroperoxide was first observed. Upon warming to room temperature, formation of aldehyde $3 \mathrm{a}$ and alcohol 2a took place. The hydroperoxide was not observed when $\mathrm{Mn}(\mathrm{dpm})_{3}$ was used. We postulate that while in both reactions the hydroperoxide may be formed, in the presence of $\mathrm{Mn}$ it undergoes rapid reduction to the alcohol, thus precluding oxidation to the aldehyde.

(39) We were also interested to find out whether 9f can be prepared via a condensation reaction. However, treatment of $(E)$-1-phenylbut2-en-1-one with $\mathrm{N}$-tosylhydrazide ( 1.1 equiv) in $\mathrm{MeOH}$ at $25{ }^{\circ} \mathrm{C}$ for $12 \mathrm{~h}$ gave $9 \mathrm{f}$ in merely $5 \%$ yield.

(40) Inoki, S.; Kato, K.; Takai, T.; Isayama, S.; Yamada, T.; Mukaiyama, T. Bis(trifluoroacetylacetonato)cobalt(II) Catalyzed Oxidation-Reduction Hydration of Olefins Selective Formation of Alcohols from Olefins. Chem. Lett. 1989, 18, 515-518.

(41) Mish, M. R.; Guerra, F. M.; Carreira, E. M. Asymmetric Dipolar Cycloadditions of $\mathrm{Me}_{3} \mathrm{SiCHN}_{2}$. Synthesis of a Novel Class of Amino Acids: Azaprolines. J. Am. Chem. Soc. 1997, 119, 8379-8380.

(42) Also, $\mathrm{HCl}$ salt 16 is thermally sensitive and does not store well. 